\title{
Gamma Knife radiosurgery for intracranial benign meningiomas: follow-up outcome in 130 patients
}

\author{
Youlin Ge, MD,' Dong Liu, MD,1 Zhiyuan Zhang, MD,' Yanhe Li, MD,, Yiguang Lin, MD,1 \\ Guokai Wang, MD, ${ }^{1}$ Yongqing Zong, MD, ${ }^{1}$ and Enhu Liu, MD ${ }^{2}$ \\ Departments of ${ }^{1}$ Neurosurgery and ${ }^{2}$ Neuroradiology, the Second Hospital of Tianjin Medical University, Tianjin, China
}

OBJECTIVE The authors retrospectively analyzed the follow-up data in 130 patients with intracranial benign meningiomas after Gamma Knife radiosurgery (GKRS), evaluated the tumor progression-free survival (PFS) rate and neurological function preservation rate, and determined the predictors by univariate and multivariate survival analysis.

METHODS This cohort of 130 patients with intracranial benign meningiomas underwent GKRS between May 2012 and May 2015 at the Second Hospital of Tianjin Medical University. The median age was 54.5 years (range 25-81 years), and women outnumbered men at a ratio of 4.65:1. All clinical and radiological data were obtained for analysis. No patient had undergone prior traditional radiotherapy or chemotherapy. The median tumor volume was $3.68 \mathrm{~cm}^{3}$ (range $0.23-$ $45.78 \mathrm{~cm}^{3}$ ). A median margin dose of $12.0 \mathrm{~Gy}$ (range 10.0-16.0 Gy) was delivered to the tumor with a median isodose line of $50 \%$ (range $50 \%-60 \%$ ).

RESULTS During a median follow-up of 36.5 months (range 12-80 months), tumor volume regressed in 37 patients $(28.5 \%)$, was unchanged in 86 patients $(66.2 \%)$, and increased in 7 patients $(5.4 \%)$. The actuarial tumor progression-free survival (PFS) rate was $98 \%, 94 \%$, and $87 \%$ at 1,3 , and 5 years, respectively, after GKRS. Tumor recurred in 7 patients at a median follow-up of 32 months (range 12-56 months). Tumor volume $\geq 10 \mathrm{~cm}^{3}(p=0.012$, hazard ratio [HR] 8.25 , $95 \% \mathrm{Cl} 1.60-42.65)$ and pre-GKRS Karnofsky Performance Scale score $<90$ ( $p=0.006, \mathrm{HR} 9.31,95 \% \mathrm{Cl} 1.88-46.22$ ) were independent unfavorable predictors of PFS rate after GKRS. Of the 130 patients, $101(77.7 \%)$ presented with one or more neurological symptoms or signs before GKRS. Neurological symptoms or signs improved in 40 (30.8\%) patients, remained stable in $83(63.8 \%)$, and deteriorated in $7(5.4 \%)$ after GKRS. Two (1.5\%) patients developed new cranial nerve $(C N)$ deficit. Tumor volume $\geq 10 \mathrm{~cm}^{3}(p=0.042, \mathrm{HR}=4.73,95 \% \mathrm{Cl} 1.06-21.17)$ and pre-GKRS CN deficit $(p=$ $0.045, \mathrm{HR}=4.35,95 \% \mathrm{Cl}$ 0.84-22.48) were independent unfavorable predictors for improvement in neurological symptoms or signs. Six (4.6\%) patients developed new or worsening peritumoral edema with a median follow-up of 4.5 months (range 2-7 months).

CONCLUSIONS GKRS provided good local tumor control and high neurological function preservation in patients with intracranial benign meningiomas. Patients with tumor volume $<10 \mathrm{~cm}^{3}$, pre-GKRS Karnofsky Performance Scale score $\geq 90$, and no pre-GKRS CN deficit (I-VIII) can benefit from stereotactic radiosurgery. It can be considered as the primary or adjuvant management of intracranial benign meningiomas.

https://thejns.org/doi/abs/10.3171/2019.3.FOCUS1956

KEYWORDS stereotactic radiosurgery; Gamma Knife radiosurgery; benign meningioma

$\mathrm{M}$ ENINGIOMA, the most common primary intracranial benign tumor in adults, ${ }^{36}$ arises from the dura mater. Currently, a craniotomy is still the preferred treatment for meningioma. The optimal outcome is to achieve a maximal resection of the tumor and for the neurological function to be left in- tact. However, it is usually difficult for neurosurgeons to achieve a gross-total resection due to large tumor size, deep tumor location, and proximity to critical structures. The overall gross-total resection rate of meningiomas in previous studies in the literature varied from $40 \%$ to $96 \%, 1,14,17,23,28,39$ and craniotomy is sometimes accompa-

ABBREVIATIONS ARE = adverse radiation effect; $\mathrm{CN}=$ cranial nerve; $\mathrm{CPA}=$ cerebellopontine angle; $\mathrm{GKRS}=\mathrm{Gamma}$ Knife radiosurgery; $\mathrm{HR}=$ hazard ratio; $\mathrm{KPS}=$ Karnofsky Performance Scale; PFS = progression-free survival; SRS = stereotactic radiosurgery.

SUBMITTED January 28, 2019. ACCEPTED March 25, 2019

INCLUDE WHEN CITING DOI: 10.3171/2019.3.FOCUS1956. 
TABLE 1. Characteristics of 130 patients with intracranial benign meningiomas treated with GKRS

\begin{tabular}{|c|c|}
\hline Characteristic & Value (\%) \\
\hline Female:male & $107: 23(82: 18)$ \\
\hline \multicolumn{2}{|l|}{ Age in yrs } \\
\hline$\geq 60$ vs $<60$ & $37: 93(28.5: 71.5)$ \\
\hline Median & 54.5 \\
\hline Range & $25-81$ \\
\hline Previous resection & $53(40.8)$ \\
\hline Previous radiotherapy & 0 \\
\hline Previous GKRS & 0 \\
\hline Symptomatic patients* & $101(77.7)$ \\
\hline Headache & $35(26.9)$ \\
\hline Dizziness & $30(23.1)$ \\
\hline CN deficit & $50(38.5)$ \\
\hline CN I & $2(1.5)$ \\
\hline $\mathrm{CN} \|$ & $16(12.3)$ \\
\hline CN III, IV, \& VI & $18(13.9)$ \\
\hline CN V & $26(20)$ \\
\hline CN VII & $1(0.8)$ \\
\hline CN VIII & $5(3.8)$ \\
\hline Limb weakness & $9(6.9)$ \\
\hline Sensory disturbance & $7(5.4)$ \\
\hline Seizure & $3(2.3)$ \\
\hline Hypomnesia & $3(2.3)$ \\
\hline Ataxia or balance disorder & $2(1.5)$ \\
\hline \multicolumn{2}{|l|}{ Tumor distribution } \\
\hline Single vs multiple & 107:23 (82.3:17.7) \\
\hline Total no. of tumors & 156 \\
\hline No previous resection & $83(53.2)$ \\
\hline Residual or progressive & $73(46.8)$ \\
\hline \multicolumn{2}{|l|}{ Tumor location } \\
\hline Convexity area & $26(16.7)$ \\
\hline Parafalcine \& parasagittal & $28(17.9)$ \\
\hline Sellar \& parasellar & $27(17.3)$ \\
\hline Petroclival & $23(14.7)$ \\
\hline CPA & $21(13.5)$ \\
\hline Tentorial & $16(10.2)$ \\
\hline Foramen magnum & $2(1.3)$ \\
\hline Sphenoidal & $10(6.4)$ \\
\hline Olfactory & $3(1.9)$ \\
\hline \multicolumn{2}{|l|}{ Tumor vol in $\mathrm{cm}^{3}$} \\
\hline$\geq 10$ vs $<10$ & $48: 108(30.8: 69.2)$ \\
\hline Median & 3.68 \\
\hline Range & $0.23-45.78$ \\
\hline \multicolumn{2}{|l|}{ No resection } \\
\hline Median & 2.6 \\
\hline Range & $0.23-21.1$ \\
\hline \multicolumn{2}{|l|}{ Residual or progressive } \\
\hline Median & 8.90 \\
\hline Range & $0.33-45.78$ \\
\hline
\end{tabular}

CONTINUED IN NEXT COLUMN »
» CONTINUED FROM PREVIOUS COLUMN

TABLE 1. Characteristics of 130 patients with intracranial benign meningiomas treated with GKRS

\begin{tabular}{cc}
\hline \multicolumn{1}{c}{ Characteristic } & Value $(\%)$ \\
\hline Median follow-up duration in mos & 36.5, range 12-80 \\
\hline KPS score & \\
\hline$<90$ vs $\geq 90$ & $15: 115(11.5: 88.5)$ \\
\hline Mean \pm SD & $90.5 \pm 6.7$ \\
\hline Range & $50-100$ \\
\hline
\end{tabular}

* 101 (77.7\%) symptomatic patients presented with one or more neurological symptoms or signs before GKRS.

nied by postoperative complications, neurological dysfunction, tumor recurrence, and death. . $^{2,4,6,18,23,24,42}$ Stereotactic radiosurgery (SRS) provides a minimal invasion, is a more efficient treatment, and has fewer complications for patients with intracranial meningiomas, and is now attracting increasing attention from neurosurgeons. SRS provides radiobiological tumor growth control by delivering highly conformal radiation in a single procedure. The sharp falloff of radiation beyond the planning target volume reduces long-term radiation-related complications. Gamma Knife radiosurgery (GKRS) is now increasingly used for the treatment of intracranial meningiomas due to its precise positioning of intracranial lesions. This is a single-center outcome study of the midterm efficacy of GKRS in the treatment of benign intracranial meningiomas.

\section{Methods}

\section{Patient Population}

This cohort was composed of 130 patients with intracranial WHO grade I meningiomas who underwent GKRS at the Second Hospital of Tianjin Medical University between May 2012 and May 2015. The characteristics and clinical features of the patients are presented in Table 1. Patients were excluded for follow-up time $<6$ months or pathological grading $\geq$ WHO grade II-exceptional cases of death due to intracranial meningioma or patients with tumor recurrence were included in spite of a follow-up period $<6$ months. All patients were diagnosed as harboring a benign meningioma based on the natural course of the disease, radiological features, and histopathology. The typical natural course of benign meningioma includes a long medical history, slow tumor progression, and no history of cancer metastasis. Radiological features include a dural tail sign, clear boundaries, and uniform contrast enhancement on MRI sequences obtained with contrast agents. Radiological features that distinguish benign meningioma from atypical or malignant meningioma include relatively small tumor volume, mild peritumoral edema, and absence of tumor necrosis, whereas atypical or malignant meningiomas often exhibit invasive growth characteristics that destroy the surrounding brain parenchyma and skull. Sometimes a conventional MRI histogram analysis based on a 3D tumor measurement can help the differential diagnosis. ${ }^{11,20,44}$ 


\section{Gamma Knife Procedure}

In this study, all patients were first evaluated by neurosurgeons and radiologists for radiosurgery. The indications for patients undergoing radiosurgery were as follows: 1) tumor diameter $<3 \mathrm{~cm}$ in patients with no severe neurological symptoms or signs; 2) residual or recurrent tumors after craniotomy; and 3) patients unwilling or unable to tolerant a resection.

A Gamma Knife Model C unit (Elekta Instruments, Inc.) was used before July 2014 and a Gamma Knife Perfexion unit (Elekta Instruments, Inc.) was used thereafter in the treatment of patients with meningiomas. The GKRS procedure began with the placement of a Leksell Model $G$ stereotactic frame (Elekta $A B$ ), which was attached to the patient's head after local anesthesia and sedation, and then 2-mm-slice, no gap, high-resolution stereotactic contrast-enhanced MRI was performed to determine the location of intracranial lesions and their relationship with surrounding critical structures. Rarely, a 64-slice CT scan was performed when the patient had a metal implant or was allergic to gadopentetate. Thin-slice axial and coronal plane images were obtained and transferred to GammaPlan Station software. Radiosurgical dose planning was performed by a neurosurgeon in conjunction with a radiation oncologist and a medical physicist. All patients in this cohort underwent a single session of SRS, tumor volume was computed by contouring the tumor and then using GammaPlan Station software, and the optimal margin dose and isodose line were determined by tumor volume and adjacent critical structures according to the dosevolume effect. The median prescribed dose delivered to the tumor margin was $12.0 \mathrm{~Gy}$ (range 10.0-16.0 Gy, <9.0 Gy for cranial nerve [CN] II) with a median isodose line of $50 \%$ (range $50 \%-60 \%$ ) and a median of 7 isocenters (range 4-28) (Table 2). Each patient was administered 40 $\mathrm{mg}$ corticosteroid intravenously before SRS.

\section{Clinical and Radiological Follow-Up}

All patients who underwent GKRS were regularly followed up on an outpatient basis every 6 months in the 1st year, and yearly thereafter if the tumor was well controlled or there was no evidence of neurological symptoms or signs of deterioration. The termination of follow-up was at tumor recurrence or the patient's death due to intracranial meningiomas. Clinical follow-up was performed by a neurosurgeon who assessed the patient's symptoms or signs, neurological function, and Karnofsky Performance Scale (KPS) score to determine whether further intervention was needed. At the time of radiological follow-up, the patients underwent a thin-slice, high-resolution enhanced MRI or CT scan, and the neuroimaging outcome was evaluated by a neurosurgeon or neuroradiologist and compared with the neuroimaging obtained at GKRS to determine whether the tumor recurred or progressed, or whether there were adverse radiation effects (AREs). AREs were defined as new or worsening peritumoral edema that shows high intensity on T2-weighted or FLAIR MRI sequences after GKRS. Parameters of tumor control were defined as 1) tumor progression (tumor volume increased $\geq 10 \%$ compared to the volume at GKRS); 2) tumor regression (tumor volume shrinkage $\geq 10 \%$ ); or 3 ) tumor unchanged (tumor
TABLE 2. GKRS treatment parameters

\begin{tabular}{cc}
\hline Characteristic & Median \pm SD (range) \\
\hline Margin dose in Gy & $12.0 \pm 1.0(10.0-16.0)$ \\
\hline Maximum dose in Gy & $24.0 \pm 2.0(18.2-32.0)$ \\
\hline Isodose line in \% & $50 \pm 2.5(50-60)$ \\
\hline No. of isocenters & $7 \pm 2.8(4-28)$ \\
\hline
\end{tabular}

volume change $<10 \%)$. ${ }^{5,30,34}$ There was no distant metastasis. Tumor volume was computed by measuring the maximum diameter at the horizontal, coronal, and sagittal planes of the MR images. Tumor volume $\left(\mathrm{cm}^{3}\right)=$ anteroposterior diameter $\times$ horizontal diameter $\times$ vertical diameter $(\mathrm{cm}) \times \pi / 6$.

\section{Statistical Analysis}

Event occurrence at follow-up was defined as tumor recurrence or progression. Description analysis of continuous variables was done using the mean or median in case of normal or nonnormal distributions, respectively, and categorical variables were described by frequencies and percentage. The follow-up time for patients with event occurrence was calculated from the first GKRS to event (tumor recurrence, tumor progression, or patient's death), and for the others it was calculated from the first GKRS to the last follow-up. All time-to-event data were calculated from the time of first GKRS to tumor recurrence, and were described with a Kaplan-Meier survival curve. Univariate Kaplan-Meier survival analysis was performed first to identify potential predictive factors for tumor recurrence or progression; variables with a $p \leq 0.2$ were considered meaningful and entered into the multivariate Cox regression analysis to assess hazard ratios (HRs). ${ }^{13}$ The multivariate proportional hazards model was built by a prior consideration of the predictors for which data were gathered. Continuous data were compared using the Student t-test; categorical data were compared using the chi-square test. All calculations were performed using commercially available statistical software (IBM SPSS Statistics 20, IBM Corp.), and p $<0.05$ was considered statistically significant.

\section{Results}

\section{Patient and Tumor Attributes}

At the time of data collection, a total of 130 patients with intracranial WHO grade I meningiomas were included in the study, among whom 2 patients died of chronic medical diseases unrelated to intracranial tumors, one at 46 and the other at 67 months after GKRS. Of the 130 patients with a median age of 54.5 years (range $25-81$ years), women outnumbered men at a ratio of 4.65:1 (107:23). A total of $77(59.2 \%)$ patients underwent GKRS as primary management, and 53 (40.8\%) patients received it as adjuvant or salvage management (45 with residual tumors and 8 with progressive tumors) after resection; the tumors in the latter group were pathologically proven to be WHO grade I meningioma. The median interval between primary resection and radiosurgery was 5 months (range 
TABLE 3. Specific alterations of tumor volume on radiological imaging after GKRS

\begin{tabular}{lrrcc}
\hline \multicolumn{1}{c}{ Characteristic } & Shrinkage & Stable & Progression & Overall (\%) \\
\hline No. of patients & 37 & 86 & 7 & 130 \\
\hline No. of tumors & 37 & 112 & 7 & 156 \\
\hline$\quad$ Convexity area & 1 & 23 & 2 & $26(16.7)$ \\
\hline $\begin{array}{l}\text { Parafalcine \& } \\
\quad \text { parasagittal }\end{array}$ & 5 & 22 & 1 & $28(17.9)$ \\
\hline Sellar \& parasellar & 11 & 16 & 0 & $27(17.3)$ \\
\hline Petroclival & 8 & 13 & 2 & $23(14.7)$ \\
\hline CPA & 6 & 15 & 0 & $21(13.5)$ \\
\hline Tentorial & 5 & 10 & 1 & $16(10.2)$ \\
\hline Foramen magnum & 0 & 2 & 0 & $2(1.3)$ \\
\hline Sphenoidal & 0 & 10 & 0 & $10(6.4)$ \\
\hline Olfactory & 1 & 1 & 1 & $3(1.9)$ \\
\hline
\end{tabular}

* 156 tumors were treated with GKRS, for 23 patients with multiple tumors.

1-52 months). There was at least one neurological symptom, sign, or $\mathrm{CN}$ deficit in $101(77.7 \%)$ patients before GKRS, including headache (26.9\%), dizziness (23.1\%), limb weakness (6.9\%), sensory disturbance (5.4\%), seizure (2.3\%), hypomnesia (2.3\%), CN deficits (I-VIII) (38.5\%), and other symptoms or signs (ataxia, balance disorder) (1.5\%). The mean KPS score was $90.5 \pm 6.7$ (range 50100) before GKRS. No patient had received prior adjuvant radiotherapy or chemotherapy.

A total of 156 tumors with a median tumor volume of $3.68 \mathrm{~cm}^{3}$ (range $\left.0.23-45.78 \mathrm{~cm}^{3}\right)$, consisting of 48 (30.8\%) large tumors (volume $\geq 10 \mathrm{~cm}^{3}$ ) and $108(69.2 \%)$ small and moderate tumors (volume $<10 \mathrm{~cm}^{3}$ ) were under treatment by GKRS. ${ }^{30}$ Categorized by tumor site, the percentages were as follows: convexity meningiomas (16.7\%), parafalcine and parasagittal meningiomas (17.9\%), sellar and parasellar meningiomas (17.3\%), petroclival meningiomas $(14.7 \%)$, cerebellopontine angle (CPA) meningiomas (13.5\%), tentorial meningiomas (10.2\%), foramen magnum meningiomas (1.3\%), sphenoidal meningiomas (6.4\%), and olfactory meningiomas $(1.9 \%){ }^{21,22,41}$ There were 73 $(46.8 \%)$ residual or progressive tumors with a median volume of $8.9 \mathrm{~cm}^{3}$ (range $0.33-45.78 \mathrm{~cm}^{3}$ ), and $83(53.2 \%)$ initial tumors with a median volume of $2.6 \mathrm{~cm}^{3}$ (range $\left.0.23-21.1 \mathrm{~cm}^{3}\right)$.

\section{Radiological Outcomes}

Radiological follow-up was usually performed in parallel with clinical follow-up. During a median follow-up duration of 36.5 (range 12-80) months, tumor volume was observed to have shrunk in 37 (28.5\%) patients, remained unchanged in $86(66.2 \%)$ patients, and increased in $7(5.4 \%)$ patients (Table 3 ). Of the patients with tumor recurrence, the median recurrence time from GKRS was 32 (12-56) months. Tumor recurred within the planning target volume in 5 patients and outside the planning target volume in 2; there was no case of distant recurrence. For further interventions, 4 of 7 patients with tumor recurrence underwent a second GKRS and the rest preferred microsurgical resections, which were then accompanied by a second GKRS for the residual tumors. All tumors were well controlled at the last follow-up.

In this study the tumor progression-free survival (PFS) rate was used to evaluate the local tumor control. Tumor PFS was defined as the time from the GKRS to tumor recurrence or progression. The cumulative PFS rates of the whole cohort at 1, 3, and 5 years by Kaplan-Meier survival analysis were $98 \%, 94 \%$, and $87 \%$, respectively. Univariate Kaplan-Meier analysis of predictive variables revealed that tumor volume $\geq 10 \mathrm{~cm}^{3}(\mathrm{p}=0.012, \mathrm{HR} 8.25,95 \%$ CI 1.60-42.65) (Fig. 1) and patient KPS score $<90(\mathrm{p}=$ 0.006, HR 9.31, 95\% CI 1.88-46.22) (Fig. 2) were independent unfavorable predictors for tumor progression, and multivariate Cox regression analysis also pointed to the same result (Table 4).

\section{Clinical Outcomes}

The number of patients with neurological symptoms, signs, or CN deficit before GKRS in this cohort was 101 (77.7\%); the specific symptoms, signs, or $\mathrm{CN}$ deficit are shown in Table 1. Among this subgroup 38 (37.6\%) patients had prior tumor resection, in which 12 patients developed new or worsening of preexisting neurological symptoms and signs after resection; and 63 (62.4\%) patients had no craniotomy history. During a median followup of 36.5 months neurological symptoms, signs, or $\mathrm{CN}$ deficit were improved in $40(30.8 \%)$ patients, remained stable in $83(63.8 \%)$, and deteriorated in 7 (5.4\%) (Table 5 ); the actuarial neurological function preservation rate was $94.62 \%$. Among the patients with deteriorative symptoms or signs, 3 patients developed new $\mathrm{CN}$ deficits after GKRS - one had facial numbness and difficulty in opening the mouth 24 months after GKRS, another developed worsening visual acuity at the 9th month, and the third patient experienced diplopia at the 16th month. All 3 patients were regularly observed every 3-6 months, and 2 of them presented with no progression in $\mathrm{CN}$ deficit, whereas the third patient developed progressive symptoms. This patient's tumor was found to recur at the 55th month of radiological follow-up, and a further craniotomy was performed. At the last follow-up, the mean KPS score of the cohort was $92.5 \pm 7.8$, compared to the mean KPS score of $90.5 \pm 6.7$ at GKRS by t-test with statistical significance $(\mathrm{p}=0.01)$.

To determine the predictive factors for neurological symptoms or signs of deterioration, univariate KaplanMeier survival analysis and multivariate Cox regression analysis were used and found that preexisting $\mathrm{CN}$ deficit ( $\mathrm{p}=0.045$, HR 4.35, 95\% CI 0.84-22.48) and tumor volume $\geq 10 \mathrm{~cm}^{3}(\mathrm{p}=0.042$, HR $4.73,95 \%$ CI $1.06-21.17)$ were independent unfavorable predictors for neurological symptoms or signs of deterioration in this cohort. Patient age, craniotomy history, pre-GKRS KPS score, and margin dose were of no statistical significance to the deterioration of neurological symptoms or signs (Table 6).

Of the 40 patients with neurological symptoms or signs who improved following GKRS, in 13 patients tumor volume shrinkage was also observed on neuroimaging; the rest had a stable tumor volume. Among the 7 patients with neurological symptoms or signs of deterioration, tumor volume increased in 4 patients and remained stable in 3. 


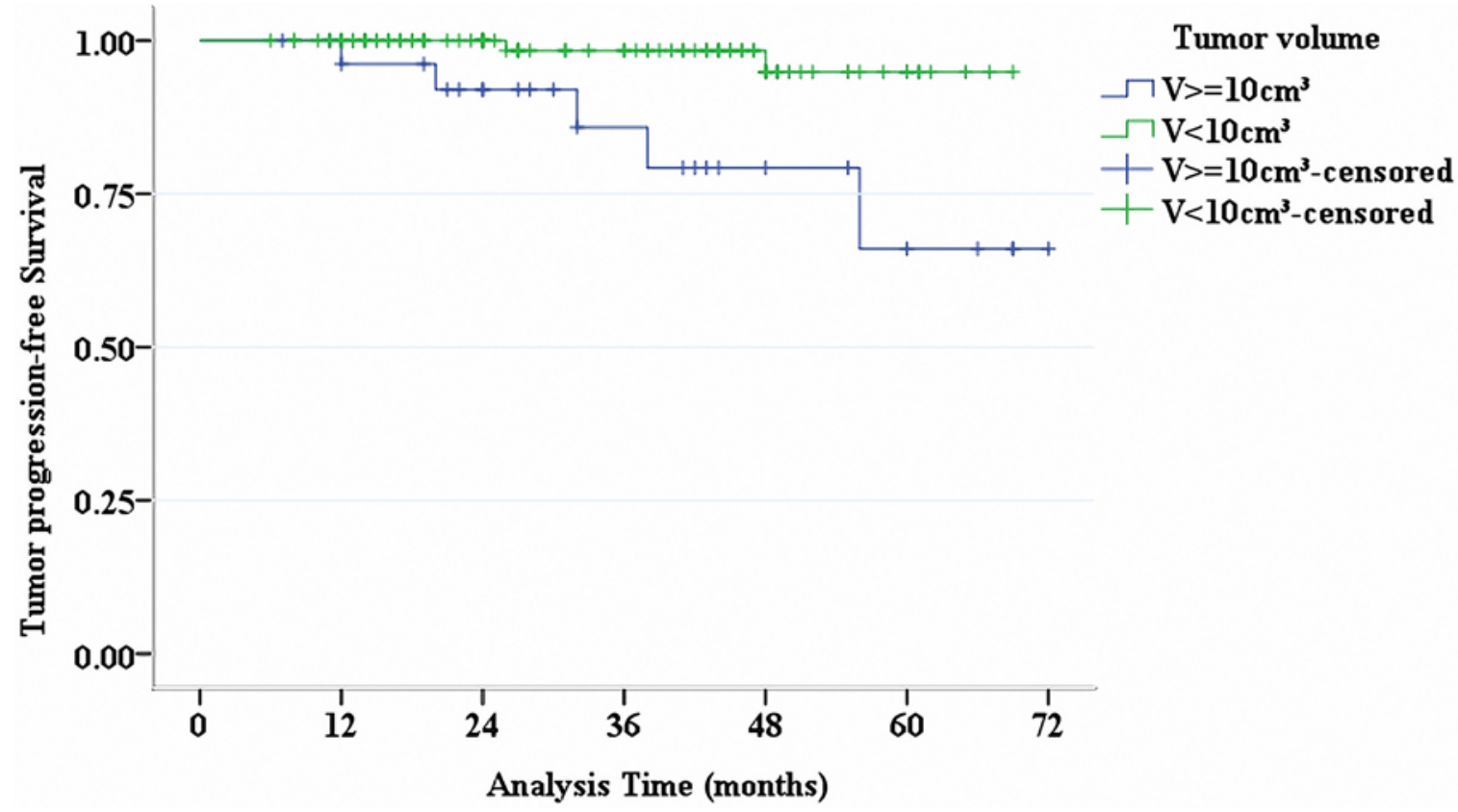

FIG. 1. Graph of tumor PFS in patients stratified by tumor volume of $10 \mathrm{~cm}^{3} . \mathrm{V}=$ volume.

Therefore, the deterioration of neurological symptoms or signs was not always consistent with the increase of tumor volume.

\section{Adverse Radiation Effects}

AREs usually include radiation-induced brain parenchymal and peritumoral edema or necrosis. There was no obvious preexisting peritumoral edema before GKRS in this cohort. During the radiological follow-up, 6 (4.6\%) patients were observed with new peritumoral edema at a median follow-up of 4.5 months (range 2-7 months), 5 of whom were asymptomatic and needed no intervention, whereas another person presented with limb weakness and was given oral corticosteroids for 1 month. All peritumoral edema lasted for a median time of 6 months (range 4-15 months) and then disappeared. We attempted to identify the predictive factors for AREs by univariate

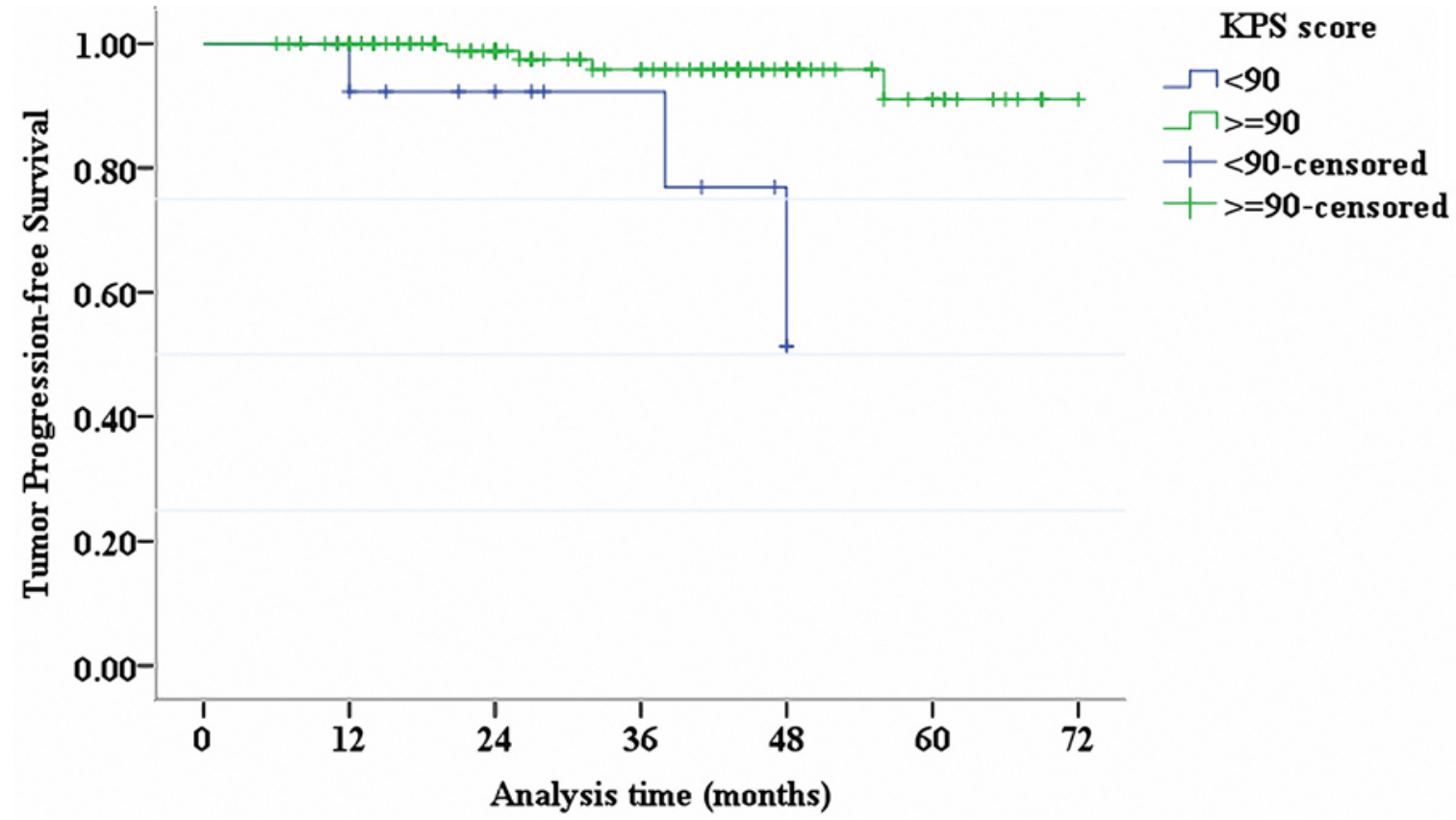

FIG. 2. Graph of tumor PFS in patients stratified by KPS score of 90. 
TABLE 4. Predictors of tumor progression after GKRS by univariate and multivariate analysis

\begin{tabular}{lll}
\hline Analysis \& Pre-GKRS Variables & $p$ Value & HR $(95 \% \mathrm{Cl})$ \\
\hline Univariate & & \\
\hline Age $(\geq 60$ vs $<60$ yrs) & 0.363 & $2.00(0.45-9.01)$ \\
\hline Prior craniotomy (yes vs no) & 0.214 & $2.84(0.55-14.72)$ \\
\hline CN deficit pre-GKRS (yes vs no) & 0.768 & $1.25(0.28-5.62)$ \\
\hline Tumor volume ( $\geq 10$ vs $\left.<10 \mathrm{~cm}^{3}\right)$ & $0.012^{*}$ & $8.25(1.60-42.65)$ \\
\hline KPS score $(<90$ vs $\geq 90)$ & $0.006^{*}$ & $9.31(1.88-46.22)$ \\
\hline Margin dose $(<12.0$ vs $\geq 12.0 \mathrm{~Gy})$ & 0.434 & $1.93(0.37-9.97)$ \\
\hline Multivariate & & \\
\hline Prior craniotomy (yes vs no) & 0.380 & $2.45(0.33-18.46)$ \\
\hline Tumor volume $\left(\geq 10\right.$ vs $\left.<10 \mathrm{~cm}^{3}\right)$ & $0.027^{*}$ & $5.97(1.62-31.44)$ \\
\hline KPS score $(<90$ vs $\geq 90)$ & $0.008^{*}$ & $7.74(2.51-26.34)$ \\
\hline * Staticaly signifant $(p<0.05)$. & &
\end{tabular}

${ }^{*}$ Statistically significant $(p<0.05)$.

and multivariate analysis, but no statistically significant outcome was found.

\section{Other Radiation Complications}

Five $(3.8 \%)$ patients experienced acute radiation toxicity within a few hours after the GKRS procedure. Two patients developed nausea and vomiting, another patient had a rapid deterioration of visual acuity, the fourth experienced transient facial paralysis, and the last had a dete-

TABLE 5. Specific alterations in clinical neurological symptoms or signs after GKRS

\begin{tabular}{|c|c|c|c|c|}
\hline Characteristic & Improvement & Stable & $\begin{array}{c}\text { New or } \\
\text { Worsening }\end{array}$ & $\begin{array}{c}\text { Overall } \\
(\%)\end{array}$ \\
\hline No. of patients & 40 & 83 & 7 & 130 \\
\hline Asymptomatic & 0 & 29 & 0 & $29(22.3)$ \\
\hline Symptomatic* & 40 & 54 & 7 & $101(77.7)$ \\
\hline Headache & 18 & 16 & 1 & $35(26.9)$ \\
\hline Dizziness & 21 & 9 & 0 & $30(23.1)$ \\
\hline Limb weakness & 3 & 5 & 1 & $9(6.9)$ \\
\hline $\begin{array}{l}\text { Sensory distur- } \\
\text { bance }\end{array}$ & 2 & 5 & 0 & $7(5.4)$ \\
\hline Seizure & 1 & 2 & 0 & $3(2.3)$ \\
\hline Hypomnesia & 0 & 3 & 0 & $3(2.3)$ \\
\hline $\mathrm{CN}$ deficit & 11 & 34 & 5 & $50(38.5)$ \\
\hline 1 & 0 & 2 & 0 & $2(1.5)$ \\
\hline II & 1 & 13 & 2 & 16 (12.3) \\
\hline III, IV, \& VI & 4 & 13 & 1 & $18(13.9)$ \\
\hline V & 7 & 17 & 2 & $26(20)$ \\
\hline VII & 0 & 1 & 0 & $1(0.8)$ \\
\hline VIII & 1 & 4 & 0 & $5(3.8)$ \\
\hline $\begin{array}{l}\text { Ataxia/balance } \\
\text { disorder }\end{array}$ & 1 & 1 & 0 & $2(1.5)$ \\
\hline
\end{tabular}

The mean KPS score was $92.5 \pm 7.8$ (range 50-100) at the last follow-up. * 101 (77.7\%) symptomatic patients presented with one or more neurological symptoms or signs before GKRS.
TABLE 6. Predictors of neurological symptoms or signs of deterioration after GKRS by univariate and multivariate analysis

\begin{tabular}{lll}
\hline Analysis \& Pre-GKRS Variables & $p$ Value & $\mathrm{HR}(95 \% \mathrm{Cl})$ \\
\hline Univariate & & \\
\hline Age $(\geq 60$ vs $<60$ yrs) & 0.979 & $0.98(0.19-5.04)$ \\
\hline Prior craniotomy (yes vs no) & 0.153 & $3.30(0.64-17.02)$ \\
\hline CN deficit pre-GKRS (yes vs no) & $0.045^{*}$ & $4.35(0.84-22.48)$ \\
\hline Tumor volume $\left(\geq 10\right.$ vs $\left.<10 \mathrm{~cm}^{3}\right)$ & $0.042^{*}$ & $4.73(1.06-21.17)$ \\
\hline KPS score $(<90$ vs $\geq 90)$ & 0.656 & $1.62(0.19-13.44)$ \\
\hline Margin dose $(<12.0$ vs $\geq 12.0 \mathrm{~Gy})$ & 0.499 & $1.76(0.34-9.09)$ \\
\hline Multivariate & & \\
\hline Prior craniotomy (yes vs no) & 0.348 & $2.30(0.40-13.13)$ \\
\hline CN deficit pre-GKRS (yes vs no) & $0.027^{*}$ & $3.2(0.57-18.35)$ \\
\hline Tumor volume $\left(\geq 10\right.$ vs $\left.<10 \mathrm{~cm}^{3}\right)$ & $0.016^{*}$ & $3.35(0.60-18.57)$ \\
\hline
\end{tabular}

${ }^{*}$ Statistically significant $(p<0.05)$.

rioration of preexisting facial numbness. Acute radiation toxicity was usually treated with corticosteroids and mannitol or glycerol fructose intravenously, and the symptoms were often relieved within 1 week. One patient developed intermittent seizures due to peritumoral edema 6 months after GKRS, and the symptoms disappeared after using corticosteroids and antiepileptic drugs intravenously for 2 days (now she takes oral antiepileptic drugs regularly to prevent further seizures). There was no evidence of distant tumor recurrence or metastasis, or of radiation-induced tumor malignancy.

\section{Discussion}

Meningioma is one of the most common intracranial primary tumors. So far, microsurgery is still the preferred treatment for meningiomas. However, gross-total resection of meningiomas-especially those located at the skull base-remains a great challenge for neurosurgeons and, in addition, microsurgery is usually accompanied with morbidity and mortality. ${ }^{19,27,43}$ SRS provides an alternative treatment for both initial and residual or progressive tumors. Because of the good local tumor control rate and neurological function preservation of SRS, more neurosurgeons accept the comprehensive treatment strategy of microsurgery combined with radiosurgery. ${ }^{9,15,25}$

Some recent studies that were focused on the treatment of intracranial meningiomas with radiosurgery reported that the local tumor control rates ranged from $88 \%$ to $100 \%$, in which $19 \%-74 \%$ of tumors shrank during a mean follow-up of 36-78 months. ${ }^{37,12,21,22,30-34,37,39-41}$ In a single-center study, Hasegawa et al. ${ }^{12}$ reported an actuarial PFS rate of $92 \%, 86 \%$, and $72 \%$ at 3,5 , and 10 years, respectively, in 67 patients. In a meta-analysis of SRS for skull base meningiomas, Starke et al. ${ }^{41}$ reviewed the outcome in 469 patients with large skull base meningiomas (> $8 \mathrm{~cm}$ ) from several centers, and reported that the actuarial tumor PFS rates at 3, 5, and 10 years were 90.3\%, 88.6\%, and $77.2 \%$, respectively. Haselsberger et al..$^{13}$ treated 20 patients with intracranial giant meningioma (median 33.3 $\mathrm{cm}^{3}$, range 13.6-79.8 $\mathrm{cm}^{3}$ ) by staged GKRS with a median margin dose of $12.0 \mathrm{~Gy}$ (range 10.0-14.0 Gy) and achieved 
a $90 \%$ local tumor control rate during a median 9.5-year follow-up. In the present study, the tumor PFS rates at 1, 3, and 5 years were $98 \%, 94 \%$, and $87 \%$, respectively, which is similar to previous studies in midterm follow-up.

For the predictors of tumor recurrence or progression, some studies revealed that increasing tumor volume was an independent predictor, which was also proved in our study. ${ }^{10,16,29}$ In this study, many patients with intracranial meningiomas had low subjective acceptance of craniotomy; even though there were significant mass effect or neurological symptoms or signs, they preferred GKRS instead of craniotomy, which resulted in a high rate of large tumor $\left(\geq 10 \mathrm{~cm}^{3}\right)$ in proportion at the time of GKRS, and reduced the treatment effect of GKRS in the cohort. In addition, a GKRS dose-plan defect may also influence local tumor control. Usually there is no clear boundary between meningioma and its adjacent dura mater, or when the tumor is in close proximity to critical structures such as CNs, major cortical draining veins, hypothalamus, and brainstem, these may lead to incomplete coverage of tumor volume within the isodose line or limitation of tumor margin dose, and then the tumor may recur or progress outside the planning target volume. In view of the great success achieved by Haselsberger et al. in treating intracranial giant meningiomas, a new strategy was provided for the treatment of intracranial large meningiomas $(\geq 10$ $\mathrm{cm}^{3}$ ) with staged GKRS.

An unexpected result of this study is that a pre-GKRS KPS score $<90$ became another unfavorable independent predictor for tumor recurrence or progression. We hypothesized that for patients with a KPS score $<90$, the initial or residual tumors were usually in close proximity to or compressing the adjacent critical structures, especially motor or language cortex, CN II, superior sagittal sinus, cavernous sinus, and brainstem, and this could lead to damage to the neurological function, which limited the coverage of tumor within the planning target volume and the margin dose delivered to tumors. This hypothesis is consistent with the outcome of clinical observations.

A favorable outcome is defined as no tumor progression and no deterioration of neurological symptoms or signs. In contrast, any tumor progression, new-onset or worsening neurological symptoms or signs, and severe AREs or radiation complication was considered an unfavorable outcome. In this study, 7 patients experienced new or worsening neurological symptoms or signs, and 2 of them were evaluated for tumor progression on neuroimaging, whereas 5 patients had tumor recurrence or progression on neuroimaging without neurological symptoms or signs of deterioration, and there were no severe AREs or radiation complications. Thus, an unfavorable outcome was observed in 12 patients $(9.2 \%)$, compared to the favorable outcome in 118 patients $(90.8 \%)$; this result is similar to the previous studies. $8,13,35$ The univariate and multivariate analysis discussed above had revealed that tumor volume $\geq 10 \mathrm{~cm}^{3}$, pre-GKRS CN deficits (I-VIII), and KPS score $<90$ were independent predictors for an unfavorable outcome.

Five patients developed acute radiation toxicity within a few hours after the GKRS procedure; symptoms or signs included headache, vomiting, damage of visual acu-
TABLE 7. Radiation-related complications following GKRS and intervention

\begin{tabular}{lrl}
\hline \multicolumn{1}{c}{ Complication } & Value (\%) & Treatment \\
\hline Acute radiation reaction & & \\
\hline Headache & $1(0.8)$ & Corticosteroid \\
\hline Vomiting & $1(0.8)$ & Corticosteroid \\
\hline Damage of visual acuity & $1(0.8)$ & Corticosteroid \\
\hline Transient peripheral facial paralysis & $1(0.8)$ & Corticosteroid \\
\hline $\begin{array}{c}\text { Deterioration of pre-existing facial } \\
\text { numbness }\end{array}$ & $1(0.8)$ & Corticosteroid \\
\hline $\begin{array}{c}\text { Peritumoral edema } \\
\text { Worsening }\end{array}$ & & \\
\hline New & 0 & \\
\hline Asymptomatic & & \\
\hline Symptomatic & $5(3.8)$ & Observation \\
\hline Overall & $1(0.8)$ & Corticosteroid \\
\hline
\end{tabular}

ity, transient peripheral facial paralysis, and worsening of preexisting facial numbness. Six patients had new peritumoral edema during a median follow-up of 4.5 months (range 2-7 months) after the GKRS procedure; the peritumoral edema disappeared within 1 year in 5 asymptomatic patients with regular observation, and after administration of corticosteroids 1 symptomatic patient was cured at the 6-month follow-up. There were no radiation-related deaths in this series. The incidence of AREs was 8.5\% (Table 7). Sheehan et al. ${ }^{38}$ reported on 212 patients who underwent GKRS for parasagittal and parafalcine meningiomas, of whom 11 patients $(5.2 \%)$ had new or worsening peritumoral edema during a median follow-up period of 19.6 months (range 6-158 months). In a multicenter study, Milano et al. ${ }^{26}$ analyzed the follow-up data of SRS on the treatment of non-skull base meningiomas and indicated that the incidence of peritumoral edema ranged from 5\% to $43 \%$ within 3-9 months following SRS. The results of these reports support the consensus that GKRS is a safe and effective treatment choice for intracranial benign meningiomas due to its low morbidity and mortality rates.

\section{Study Limitations}

The present work is a retrospective cohort study with inherent selection bias - patients who underwent GKRS as primary treatment in this cohort lacked histopathological evidence, and imaging-based diagnosis of meningiomas does not guarantee a completely accurate diagnosis and distinguish between benign and atypical meningiomas, which may lead to the inclusion of other intracranial benign tumors such as schwannomas. This study had a long time span, and during this time the center experienced staff turnover, instrument and software upgrades, and improvement in SRS techniques, which may have an influence on the treatment strategy. In addition, there was not a uniform objective standard for the assessment of neurological symptoms or signs, and an accurate algorithm for tumor volume on neuroimaging was lacking, which may lead to outcome data bias. The follow-up time was not long enough to estimate the long-term outcome of GKRS on 
meningiomas. Finally, this is a single-center study, so the results are not scalable.

\section{Conclusions}

GKRS provides a safe and effective solution for intracranial WHO grade I meningioma with its good local tumor control, high neurological function preservation, and low morbidity and mortality rates. Patients with tumor volume $<10 \mathrm{~cm}^{3}$, pre-GKRS KPS score $\geq 90$, and no pre-GKRS CN deficits (I-VIII) can benefit from GKRS. Therefore, it can be considered a primary treatment for asymptomatic patients with tumor volume $<10 \mathrm{~cm}^{3}$, an alternative treatment for patients who are subjectively unwilling or unable to undergo craniotomy, or as an adjuvant treatment of residual and progressive tumor after craniotomy. We expect more data from multiple centers and longer follow-up time to support this conclusion.

\section{References}

1. Brokinkel B, Holling M, Spille DC, Heß K, Sauerland C, Bleimüller C, et al: Surgery for meningioma in the elderly and long-term survival: comparison with an age- and sexmatched general population and with younger patients. J Neurosurg 126: 1201-1211, 2017

2. Castlen JP, Cote DJ, Zaidi HA, Laws ER Jr: The extended, transnasal, transsphenoidal approach for anterior skull base meningioma: considerations in patient selection. Pituitary 20:561-568, 2017

3. Cohen-Inbar O, Lee CC, Sheehan JP: The contemporary role of stereotactic radiosurgery in the treatment of meningiomas. Neurosurg Clin N Am 27:215-228, 2016

4. Couldwell WT: Left occipital craniotomy for resection of falcotentorial meningioma. Neurosurg Focus 43 (Video Suppl 2):V9, 2017

5. Couldwell WT, Cole CD, Al-Mefty O: Patterns of skull base meningioma progression after failed radiosurgery. J Neurosurg 106:30-35, 2007

6. Elarjani T, Shetty R, Singh H, da Silva HB, Sekhar LN: Transpetrosal approach to petro-clival meningioma. Neurosurg Focus 43 (Video Suppl 2):V1, 2017

7. Gande A, Kano H, Bowden G, Mousavi SH, Niranjan A, Flickinger JC, et al: Gamma Knife radiosurgery of olfactory groove meningiomas provides a method to preserve subjective olfactory function. J Neurooncol 116:577-583, 2014

8. Ganz JC, Reda WA, Abdelkarim K: Gamma Knife surgery of large meningiomas: early response to treatment. Acta Neurochir (Wien) 151:1-8, 2009

9. Gatterbauer B, Gevsek S, Höftberger R, Lütgendorf-Caucig C, Ertl A, Mallouhi A, et al: Multimodal treatment of parasagittal meningiomas: a single-center experience. J Neurosurg 127:1249-1256, 2017

10. Hafez RF, Morgan MS, Fahmy OM: Stereotactic Gamma Knife surgery safety and efficacy in the management of symptomatic benign confined cavernous sinus meningioma. Acta Neurochir (Wien) 157:1559-1564, 2015

11. Hale AT, Wang L, Strother MK, Chambless LB: Differentiating meningioma grade by imaging features on magnetic resonance imaging. J Clin Neurosci 48:71-75, 2018

12. Hasegawa H, Hanakita S, Shin M, Koga T, Takahashi W, Nomoto AK, et al: Single-fractionated stereotactic radiosurgery for intracranial meningioma in elderly patients: 25-year experience at a single institution. Oper Neurosurg (Hagerstown) 14:341-350, 2018

13. Haselsberger K, Maier T, Dominikus K, Holl E, Kurschel S, Ofner-Kopeinig P, et al: Staged gamma knife radiosurgery for large critically located benign meningiomas: evaluation of a series comprising 20 patients. J Neurol Neurosurg Psychiatry 80:1172-1175, 2009

14. Itamura K, Chang KE, Lucas J, Donoho DA, Giannotta S, Zada G: Prospective clinical validation of a meningioma consistency grading scheme: association with surgical outcomes and extent of tumor resection. J Neurosurg [epub ahead of print December 14, 2018; DOI: 10.3171/2018.7.JNS1838]

15. Iwai Y, Yamanaka K, Morikawa T, Ishiguro T, Honda Y, Matsusaka Y, et al: [The treatment for asymptomatic meningiomas in the era of radiosurgery.] No Shinkei Geka 31:891-897, 2003 (Japanese)

16. Jang CK, Jung HH, Chang JH, Chang JW, Park YG, Chang WS: Long-term results of gamma knife radiosurgery for intracranial meningioma. Brain Tumor Res Treat 3:103-107, 2015

17. Karsy M, Raheja A, Eli I, Guan J, Couldwell WT: Clinical outcomes with transcranial resection of the tuberculum sellae meningioma. World Neurosurg 108:748-755, 2017

18. Kwinta BM, Krzyżewski RM, Kliś KM, Dragan MR, Donicz P, Gackowska M, et al: Predictive factors of complications post intracranial meningioma surgery leading to early unplanned reoperations - a single center study. Folia Med Cracov 58:5-13, 2018

19. Li PL, Mao Y, Zhu W, Zhao NQ, Zhao Y, Chen L: Surgical strategies for petroclival meningioma in 57 patients. Chin Med J (Engl) 123:2865-2873, 2010

20. Li X, Miao Y, Han L, Dong J, Guo Y, Shang Y, et al: Meningioma grading using conventional MRI histogram analysis based on 3D tumor measurement. Eur J Radiol 110:45-53, 2019

21. Liu A, Kuhn EN, Lucas JT Jr, Laxton AW, Tatter SB, Chan MD: Gamma Knife radiosurgery for meningiomas in patients with neurofibromatosis Type 2. J Neurosurg 122:536-542, 2015

22. Mansouri A, Larjani S, Klironomos G, Laperriere N, Cusimano M, Gentili F, et al: Predictors of response to Gamma Knife radiosurgery for intracranial meningiomas. J Neurosurg 123:1294-1300, 2015

23. Meling TR, Da Broi M, Scheie D, Helseth E: Skull base versus non-skull base meningioma surgery in the elderly. Neurosurg Rev [epub ahead of print], 2018

24. Mendez-Rosito D: The supra/infra transtentorial transfalcine approach for the removal of a falcotentorial meningioma: 2-dimensional video. Oper Neurosurg (Hagerstown) [epub ahead of print], 2018

25. Metellus P, Regis J, Muracciole X, Fuentes S, Dufour H, Nanni I, et al: Evaluation of fractionated radiotherapy and gamma knife radiosurgery in cavernous sinus meningiomas: treatment strategy. Neurosurgery 57:873-886, 2005

26. Milano MT, Sharma M, Soltys SG, Sahgal A, Usuki KY, Saenz JM, et al: Radiation-induced edema after singlefraction or multifraction stereotactic radiosurgery for meningioma: a critical review. Int J Radiat Oncol Biol Phys 101:344-357, 2018

27. Otani N, Muroi C, Yano H, Khan N, Pangalu A, Yonekawa Y: Surgical management of tuberculum sellae meningioma: role of selective extradural anterior clinoidectomy. Br J Neurosurg 20:129-138, 2006

28. Pallini R, Fernandez E, Lauretti L, Doglietto F, D'Alessandris QG, Montano N, et al: Olfactory groove meningioma: report of 99 cases surgically treated at the Catholic University School of Medicine, Rome. World Neurosurg 83:219-31.e1, 3, 2015

29. Park HR, Lee JM, Park KW, Kim JH, Jeong SS, Kim JW, et al: Fractionated Gamma Knife radiosurgery as initial treatment for large skull base meningioma. Exp Neurobiol 27:245-255, 2018

30. Park KJ, Kano H, Iyer A, Liu X, Tonetti DA, Lehocky C, 
et al: Gamma Knife stereotactic radiosurgery for cavernous sinus meningioma: long-term follow-up in 200 patients. J Neurosurg [epub ahead of print July 20, 2018; DOI: 10.3171/2018.2.JNS172361]

31. Park SH, Kano H, Niranjan A, Flickinger JC, Lunsford LD: Stereotactic radiosurgery for cerebellopontine angle meningiomas. J Neurosurg 120:708-715, 2014

32. Park SH, Kano H, Niranjan A, Monaco E III, Flickinger JC, Lunsford LD: Gamma Knife radiosurgery for meningiomas arising from the tentorium: a 22-year experience. J Neurooncol 121:129-134, 2015

33. Patibandla MR, Lee CC, Sheehan J: Stereotactic radiosurgery of central skull base meningiomas-volumetric evaluation and long-term outcomes. World Neurosurg 108:176-184, 2017

34. Patibandla MR, Lee CC, Tata A, Addagada GC, Sheehan JP: Stereotactic radiosurgery for WHO grade I posterior fossa meningiomas: long-term outcomes with volumetric evaluation. J Neurosurg 129:1249-1259, 2018

35. Pendl G, Unger F, Papaefthymiou G, Eustacchio S: Staged radiosurgical treatment for large benign cerebral lesions. J Neurosurg 93 (Suppl 3):107-112, 2000

36. Pollock BE, Stafford SL: Results of stereotactic radiosurgery for patients with imaging defined cavernous sinus meningiomas. Int J Radiat Oncol Biol Phys 62:1427-1431, 2005

37. Pollock BE, Stafford SL, Link MJ: Stereotactic radiosurgery of intracranial meningiomas. Neurosurg Clin N Am 24:499-507, 2013

38. Sheehan JP, Cohen-Inbar O, Ruangkanchanasetr R, Bulent Omay S, Hess J, Chiang V, et al: Post-radiosurgical edema associated with parasagittal and parafalcine meningiomas: a multicenter study. J Neurooncol 125:317-324, 2015

39. Sheehan JP, Starke RM, Kano H, Barnett GH, Mathieu D, Chiang V, et al: Gamma Knife radiosurgery for posterior fossa meningiomas: a multicenter study. J Neurosurg 122:1479-1489, 2015

40. Sheehan JP, Williams BJ, Yen CP: Stereotactic radiosurgery for WHO grade I meningiomas. J Neurooncol 99:407-416, 2010

41. Starke RM, Przybylowski CJ, Sugoto M, Fezeu F, Awad AJ, Ding D, et al: Gamma Knife radiosurgery of large skull base meningiomas. J Neurosurg 122:363-372, 2015

42. Steinberger J, Bronheim RS, Vempati P, Oermann EK, Ladner TR, Lee NJ, et al: Morbidity and mortality of meningioma resection increases in octogenarians. World Neurosurg 109:e16-e23, 2018

43. Zada G, Başkaya MK, Shah MV: Introduction: surgical management of skull base meningiomas. Neurosurg Focus 43 (Video Suppl 2): 2017

44. Zhang T, Yu JM, Wang YQ, Yin DD, Fang LJ: WHO grade I meningioma subtypes: MRI features and pathological analysis. Life Sci 213:50-56, 2018

\section{Disclosures}

The authors report no conflict of interest concerning the materials or methods used in this study or the findings specified in this paper.

\section{Author Contributions}

Conception and design: D Liu, Ge, Zhang, Wang. Acquisition of data: Ge, Zhang, Lin. Analysis and interpretation of data: Ge, Wang. Drafting the article: Ge. Critically revising the article: D Liu. Reviewed submitted version of manuscript: all authors. Approved the final version of the manuscript on behalf of all authors: D Liu. Statistical analysis: Li, Lin, Zong. Administrative/technical/material support: D Liu, Ge, Zhang, Li, Lin, Wang, Zong. Study supervision: D Liu, Zhang.

\section{Correspondence}

Dong Liu: The Second Hospital of Tianjin Medical University, Tianjin, China.mrliudong@126.com. 